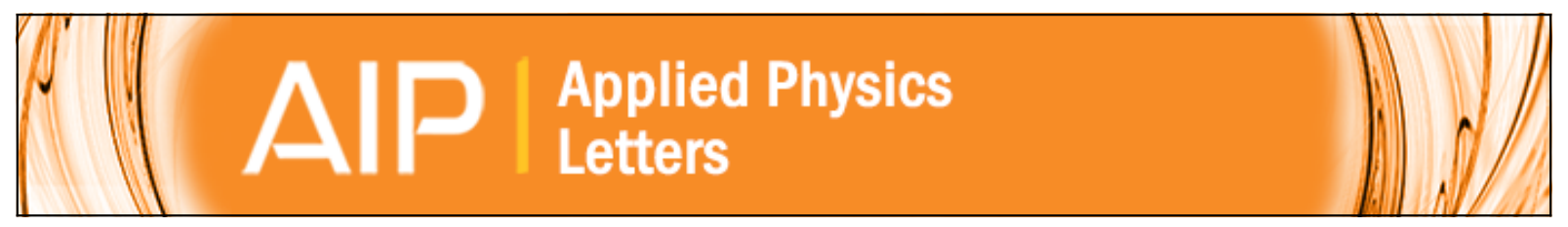

\title{
Photocontrolled wettability changes in polymer microchannels doped with photochromic molecules
}

Lucia Caprioli, Elisa Mele, Francesco Elio Angilè, Salvatore Girardo, Athanassia Athanassiou, Andrea Camposeo

, Roberto Cingolani, and Dario Pisignano

Citation: Applied Physics Letters 91, 113113 (2007); doi: 10.1063/1.2784191

View online: http://dx.doi.org/10.1063/1.2784191

View Table of Contents: http://scitation.aip.org/content/aip/journal/apl/91/11?ver=pdfcov

Published by the AIP Publishing

Articles you may be interested in

Wicking flow through microchannels

Phys. Fluids 23, 122108 (2011); 10.1063/1.3671739

Corner liquid imbibition during capillary penetration in lithographically made microchannels

Appl. Phys. Lett. 94, 171901 (2009); 10.1063/1.3123804

Droplet dynamics in a microchannel subjected to electrocapillary actuation

J. Appl. Phys. 101, 104901 (2007); 10.1063/1.2732431

Capillary pinching in a pinched microchannel

Phys. Fluids 19, 033101 (2007); 10.1063/1.2709704

Electric-field-induced steering of conducting polymer dispersion in microchannels

Appl. Phys. Lett. 88, 073506 (2006); 10.1063/1.2171797
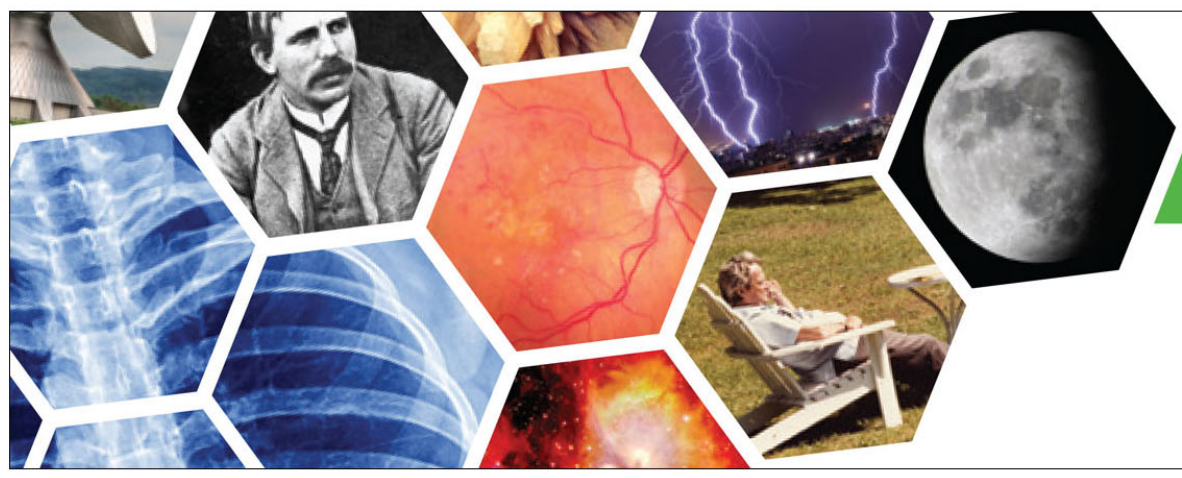

\section{SUBSCRIBE TO \\ physics \\ today}




\title{
Photocontrolled wettability changes in polymer microchannels doped with photochromic molecules
}

\author{
Lucia Caprioli, ${ }^{a}$ Elisa Mele, Francesco Elio Angilè, Salvatore Girardo, \\ Athanassia Athanassiou, Andrea Camposeo, Roberto Cingolani, and Dario Pisignano \\ National Nanotechnology Laboratory (NNL) of CNR-INFM, Università degli Studi del Salento, clo Distretto \\ Tecnologico ISUFI, via Arnesano, I-73100 Lecce, Italy
}

(Received 19 June 2007; accepted 22 August 2007; published online 14 September 2007)

\begin{abstract}
The authors demonstrate the possibility to control the fluid flow inside microfluidic networks by photoresponsive capillaries. The approach relies on the use of photochromic molecules undergoing reversible changes in their polarity when irradiated with light of specific wavelength, thus varying the wettability of cyclic olefin copolymer microchannels. The realized photoresponsive elements exhibit a decrease up to $20^{\circ}$ between the water contact angles of the native and the irradiated surfaces, which could be exploited for enhancing the penetration flow rate of fluids inside microfluidic channels up to $25 \%$. The photocontrollable microfluidic circuitry presents on-off valve behavior, allowing or blocking liquid filling processes on the base of optical control, thus allowing one to manipulate liquid flow within microfluidic networks without mechanical actuation parts. () 2007 American Institute of Physics. [DOI: 10.1063/1.2784191]
\end{abstract}

Microfluidics is a growing scientific area and a basic technology for the development of miniaturized chips for biological and chemical applications. ${ }^{1}$ Main advantages of microfluidics include low costs and reagents consumption, higher reaction efficiency and throughput than macroscopic systems, and high surface area-to-volume ratio. However, working with small (picoliter-microliter) liquid volumes in microfabricated capillaries (width in the range of $1-100 \mu \mathrm{m})$ is challenging in terms of controlling the solidfluid interfacial properties and, consequently, precisely handling the fluid flow. For manipulating and transporting liquids within microfluidic networks, besides mechanical elements such as pumps and valves, ${ }^{2}$ some methods were recently proposed, including optical, ${ }^{3-10}$ thermal, ${ }^{11,12}$ chemical, ${ }^{13}$ and electrochemical ${ }^{14}$ approaches.

In particular, significant efforts were devoted to realize reversible fluidic switches with tuneable wettability, ${ }^{15}$ and different surface functionalizations were employed in order to tailor wettability, ${ }^{16-18}$ and to produce hydrophobichydrophilic contrast inside microchannels. Zhao et al. ${ }^{19}$ combined multistream laminar flow, self-assembled monolayer chemistry, and photolithographic methods for confining liquid flow inside a microfabricated capillary. Besson et al. ${ }^{20}$ used ultraviolet (UV) irradiation to produce selective changes of wettability inside microchannels. Lahann et al. ${ }^{21}$ designed a reversible switching surface based on singlelayered molecules undergoing conformational transitions between hydrophilic and hydrophobic states in response to an electrical potential. Other techniques for driving fluids included asymmetrical photoirradiation of surfaces covered with photochromic azobenzene monolayers ${ }^{22}$ and coatings obtained by copolymerization or molecule immobilization. ${ }^{23}$ All of these approaches typically require specific synthesis or surface chemistry, alternative methods combining easy manufacturing for microfluidic chips and capability of fluid manipulation being therefore highly desirable.

In this letter, we report on the control of fluid penetration into microchannels, achievable by photoresponsive capillar-

${ }^{a)}$ Electronic mail: lucia.caprioli@unile.it ies fabricated without surface functionalization. The approach relies on the use of photochromic molecules undergoing reversible changes in their polarity when irradiated with light of specific wavelength, ${ }^{24}$ and consequently varying the wettability of polymeric microchannel walls in which they are embedded. Such photoresponsive elements exhibit a decrease up to $20^{\circ}$ between the water contact angles of the native and the irradiated surfaces. The wettability changes are employed to control the penetration dynamics of hydrophilic polyurethane inside microfluidic channels, with a measured enhancement of the flow rate up to $25 \%$. The realized photoactivable microfluidic circuitry presents on-off valve behavior, allowing or blocking liquid filling processes on the base of optical control.

Our photoresponsive system is constituted by $1^{\prime}, 3^{\prime}$ dihydro-1', 3 ' , 3' -trimethyl-6-nitrospiro[2 $H$-1-benzopyran$2,2^{\prime}$-(2H)-indole] $\left(6-\mathrm{NO}_{2}\right.$-BIPS) as photochromic molecule, embedded in the cyclic olefin copolymer, thermoplastic olefin polymer of amorphous structure (TOPAS $®$ ) as hosting matrix. 6- $\mathrm{NO}_{2}$-BIPS can exist in a "closed," colorless, and nonpolar [spiropyran (SP)] and in an "open," polar, and zwitterionic [merocyanine state (MC)] form, the passage from one to the other state occurring upon photon irradiation. The SP form undergoes isomerization producing the MC form upon exposure to UV light (wavelength about $300 \mathrm{~nm}$ ). The MC molecule typically absorbs at $530 \mathrm{~nm}$ and backconverts to SP upon exposure to green light. TOPAS ${ }^{\circledR}$ shows high chemical resistance, optical transparency also in the UV $(>90 \%$ transmission at $320 \mathrm{~nm})$, and mechanical strength, being largely used to fabricate microfluidic devices ${ }^{25}$ for its cheapness and processability. It is soluble in many organic solvents and particularly in toluene, which is also well suitable for 6- $\mathrm{NO}_{2}$-BIPS; hence, 6- $\mathrm{NO}_{2}$-BIPS/TOPAS ${ }^{\circledR}$ solutions with different relative concentrations ranging from $20 \%$ to $50 \%(\mathrm{w} / \mathrm{w})$ could easily be obtained. Combinations of $6-\mathrm{NO}_{2}$-BIPS and thermoplastic ${ }^{24,26}$ or photoresponsive ${ }^{27}$ polymers have been previously used for achieving photoinduced actuation and enhanced wettability by surface nanostructuring. For fabricating our microfluidic device, parallel microchannels with $2 \mu \mathrm{m}$ in depth $(h), 10 \mu \mathrm{m}$ in width $(w)$, 

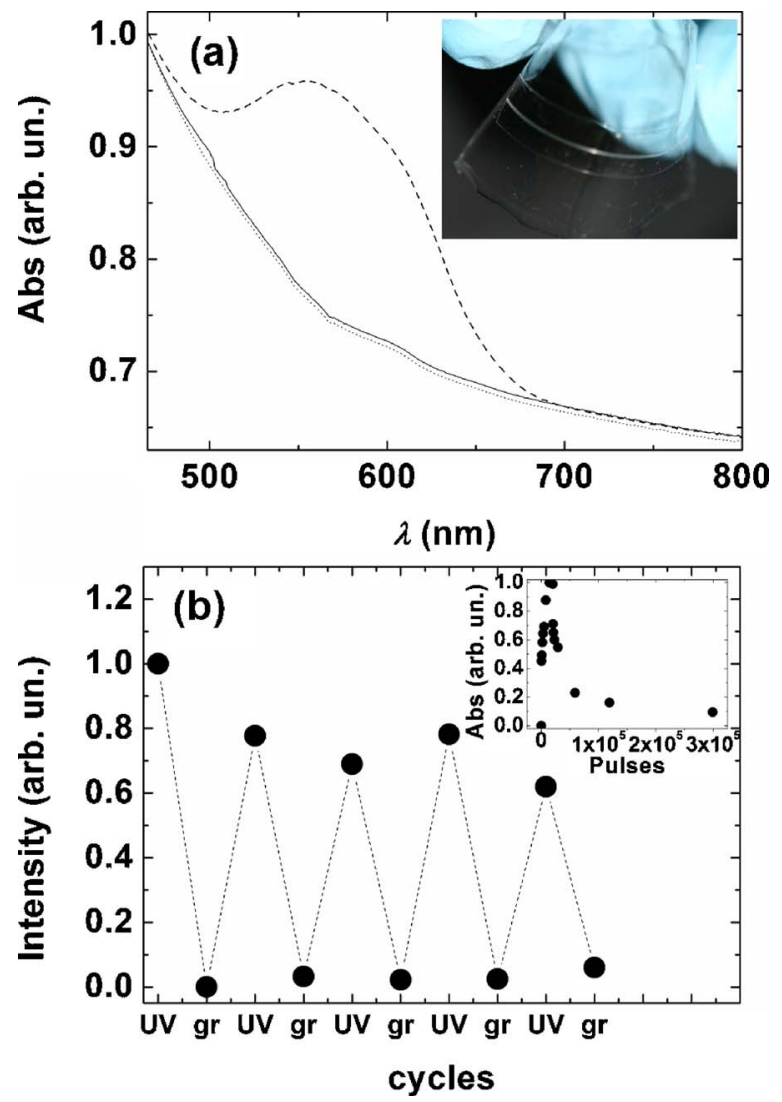

FIG. 1. (Color online) (a) Absorption spectrum of 6- $\mathrm{NO}_{2}$-BIPS/TOPAS $®$ before irradiation (dotted line), after irradiation with UV light (dashed lines) and after subsequent green irradiation (continuous line). Inset: photograph of photocontrollable 6- $\mathrm{NO}_{2}$-BIPS/TOPAS ${ }^{\circ}$ microfluidic chip while bended. (b) Cyclic photoisomerization of $6-\mathrm{NO}_{2}$-BIPS/TOPAS ${ }^{\circledR}$ through integrated absorption, measured upon alternatively irradiating by UV $\left(1.4 \times 10^{4}\right.$ pulses $)$ and green $\left(3.0 \times 10^{5}\right.$ pulses) laser light. Inset: normalized absorbance vs number of excitation laser pulses with $\lambda=355 \mathrm{~nm}$ (from 0 to $1.4 \times 10^{4}$ pulses) and $532 \mathrm{~nm}$ (after $1.4 \times 10^{4}$ pulses).

and $1.5 \mathrm{~cm}$ in length were textured in the thermoplastic blend material by replica molding ${ }^{28}$ from a photographically made resist (SU-8) master template. The capillaries were then defined by thermal sealing $\left(T=70^{\circ} \mathrm{C}\right.$ for $\left.1 \mathrm{~min}\right)$ with a flat blend layer, previously spin cast onto a glass substrate, which provided a mechanically stable, flexible microfluidic assembly [inset of Fig. 1(a)]. The UV and green exposure doses for the forth- and back-SP/MC conversions were delivered by the third $(355 \mathrm{~nm})$ and the second $(532 \mathrm{~nm})$ harmonic of a $Q$-switched neodymium-doped yttrium aluminum garnet microlaser, with a repetition rate of $100 \mathrm{~Hz}$ and a pulse width of $0.6 \mathrm{~ns}$.

We first noticed that 6- $\mathrm{NO}_{2}$-BIPS in the TOPAS ${ }^{\circ}$ matrix well retains its photochromic behavior, exhibiting a clear absorption peak at $548 \mathrm{~nm}$ upon UV irradiation [Fig. 1(a)], which is a signature of the MC species. The exposure to green light restores the original SP state, resulting in the complete quenching of the absorption in the visible range [inset of Fig. 1(b)], with a good reversibility of the photochromic reaction for several UV/green cycles, as displayed in Fig. 1(b).

For analyzing the resulting wetting properties, contact angle measurements were carried out on both native TOPAS ${ }^{\circledR}$ and 6- $\mathrm{NO}_{2}$-BIPS/TOPAS ${ }^{\circledR}$ surfaces, and upon UV and green laser irradiation. Water contact angles on TOPAS ${ }^{\circledR}$ remain unaltered after and before UV irradiation, around a value $(103 \pm 1)^{\circ}$, whereas polymeric surfaces doped with the

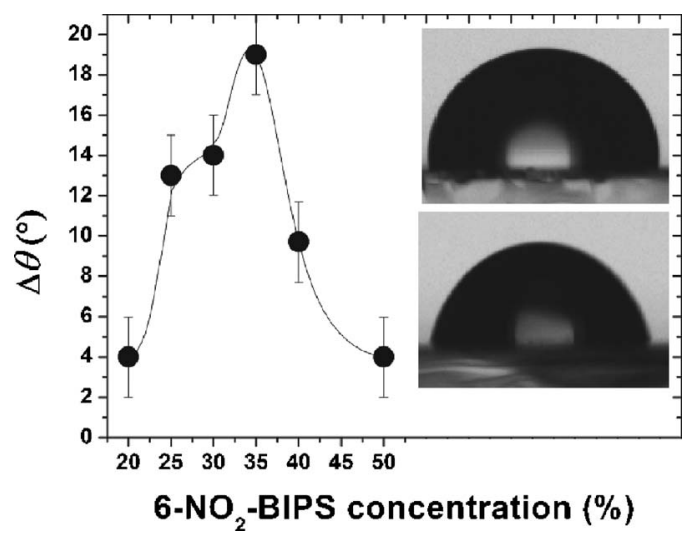

FIG. 2. Contact angle reduction on 6-NO $\mathrm{NO}_{2}$-BIPS/TOPAS® surfaces upon UV exposure (by $1.4 \times 10^{4}$ pulses) vs w/w relative concentration. The continuous line is a guide for the eye. Insets: photographs of water drops on $35 \% 6-\mathrm{NO}_{2}$-BIPS/TOPAS ${ }$, before (top inset) and after (bottom inset) UV exposure.

photochromic molecules exhibit an increase of their hydrophilicity upon UV exposure, corresponding to a contact angle decrease between $4^{\circ}$ and $20^{\circ}$, depending on the 6$\mathrm{NO}_{2}$-BIPS relative concentration (Fig. 2 and Table I). In particular, samples with $35 \%(\mathrm{w} / \mathrm{w})$ 6- $\mathrm{NO}_{2}$-BIPS/TOPAS ${ }^{\circledR}$ show contact angles of $(99 \pm 1)^{\circ}$ and $(80 \pm 1)^{\circ}$, therefore switching from a hydrophobic to a hydrophilic behavior, before and after UV irradiation, respectively (photographs in the insets of Fig. 2). All the doped samples converts back to the initial value of their water contact angle (around 98 ${ }^{\circ}$ ) upon irradiation at $532 \mathrm{~nm}$. Hence, one concludes that the observed variation of the wettability of the 6- $\mathrm{NO}_{2}$-BIPS/ TOPAS ${ }^{\circledR}$ surfaces is strictly related to the embedded photochromic molecules, and that commutating surfaces with switchable wettability can be obtained by this approach.

As proof of concept, we measured the flow rate of a hydrophilic polyurethane (Norland Optical Adhesive) inside our photoresponsive microchannels. Indeed, the surface wettability directly affects the penetration dynamics of fluids within capillaries through the contact angle $(\theta)$ entering in the law, ${ }^{29} d z / d t=(R \gamma \cos \theta) / 2 \eta z$, where $z, \eta, R$, and $\gamma$ indicate the length of the column of liquid inside the capillary at time $t$, the liquid viscosity, the hydraulic radius of the capillary, and the liquid-vapor interfacial free energy of the fluid, respectively. A $5 \mu \mathrm{l}$ polyurethane drop was released at the edge of 6- $\mathrm{NO}_{2}$-BIPS/TOPAS ${ }^{\circledR}$ microchannels, which were then spontaneously filled by capillarity action. The filling rate during the capillary rise was observed by optical microscopy through a lateral ruler integrated in the chip, having parallel ticks separated by $50 \mu \mathrm{m}$. A homemade software allowed us to determine the exact position of the front fluid along the microchannel during the filling process. Before

TABLE I. Contact angles before and after the UV exposure for different w/w 6-NO ${ }_{2}$-BIPS/TOPAS ${ }^{\circ}$ concentrations.

\begin{tabular}{lccc}
\hline $\begin{array}{l}\text { w/w 6-NO } \\
\text { concentration }(\%)\end{array}$ & $\begin{array}{c}\theta \text { before exposure } \\
\left({ }^{\circ}, \pm 1^{\circ}\right)\end{array}$ & $\begin{array}{c}\theta \text { after exposure } \\
\left({ }^{\circ}, \pm 1^{\circ}\right)\end{array}$ & $\begin{array}{c}\Delta \theta \\
\left({ }^{\circ}, \pm 2^{\circ}\right)\end{array}$ \\
\hline 20 & 98 & 93 & 5 \\
25 & 98 & 85 & 13 \\
30 & 98 & 84 & 14 \\
35 & 99 & 80 & 19 \\
40 & 98 & 88 & 10 \\
50 & 99 & 95 & 10 \\
\hline
\end{tabular}




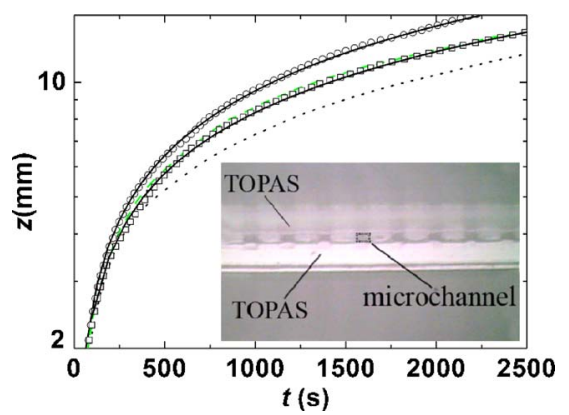

FIG. 3. (Color online) Experimental $(z, t)$ curves describing the capillary action of Norland Optical Adhesive into native TOPAS ${ }^{\circledR}$ (dotted line), native 6- $\mathrm{NO}_{2}$-BIPS/TOPAS ${ }^{\circledR}$ (squares), UV-irradiated 6- $\mathrm{NO}_{2}$-BIPS/TOPAS ${ }^{\circledR}$ (circles), and subsequently green-irradiated (green dashed line) microchannels. The continuous lines on circles and squares are the corresponding fitting curves by a $z=A t^{1 / 2}$ law. The vertical scale is on a logarithmic scale for clarity reasons. Inset: device graph displaying the microchannel $\left(2 \times 10 \mu \mathrm{m}^{2}\right.$ cross section) geometry.

measurements, the microchannels were irradiated by an UV or green excitation stripe, as long as the microfluidic device. Figure 3 shows the typical collected capillary curves $(z, t)$. The liquid fills $10 \mathrm{~mm}$ along TOPAS ${ }^{\circledR}$ microchannels in about $1800 \mathrm{~s}$ (average velocity $\bar{v}$ of $5.5 \mu \mathrm{m} / \mathrm{s}$ ), regardless the eventual UV exposure, as further evidence that the UV irradiation does not affect the polymer wettability properties. Upon polyurethane filling nonirradiated 6- $\mathrm{NO}_{2}-\mathrm{BIPS} /$ TOPAS ${ }^{\circledR}$ capillaries, the average velocity is $7.2 \mu \mathrm{m} / \mathrm{s}$, with a flow rate of $3 \mu \mathrm{m} / \mathrm{s}$, measured at the end of the microchannels. After UV exposure, $\bar{v}$ increases to $9.2 \mu \mathrm{m} / \mathrm{s}$, with a final flow rate value of about $4 \mu \mathrm{m} / \mathrm{s}$. Therefore, a penetration process faster by $25 \%$ than in native capillaries was found in UV-irradiated 6- $\mathrm{NO}_{2}$-BIPS/TOPAS ${ }^{\circledR}$ capillary walls. All the collected experimental curves are fitted by the penetration equation (fitting lines in Fig. 3), $z=A t^{1 / 2}$, where $A \approx(\Delta p / \eta)^{1 / 2}$ and $\Delta p$ is the effective pressure difference driving the capillary motion. In our experiments, $\Delta p$ is enhanced by a factor around 1.3 upon UV irradiation $\left\{\Delta p(\mathrm{MC})=[A(\mathrm{MC}) / A(\mathrm{SP})]^{2} \Delta p(\mathrm{SP})\right\}$. We point out that the native wettability behavior is fully recovered by exposition to green light, the resulting $(z, t)$ curve superimposing with the curve obtained in native (unexposed) 6- $\mathrm{NO}_{2}-\mathrm{BIPS} /$ TOPAS $®$ microchannels.

By this approach, we also demonstrated the possibility to switch on the flow of water inside microfluidic channels. For instance, water is unable to penetrate unexposed 6$\mathrm{NO}_{2}$-BIPS/TOPAS® capillaries due to their hydrophobic character [Fig. 4(a)]. Instead, because of the remarkable increase of surface hydrophilicity (Table I), water starts flow-

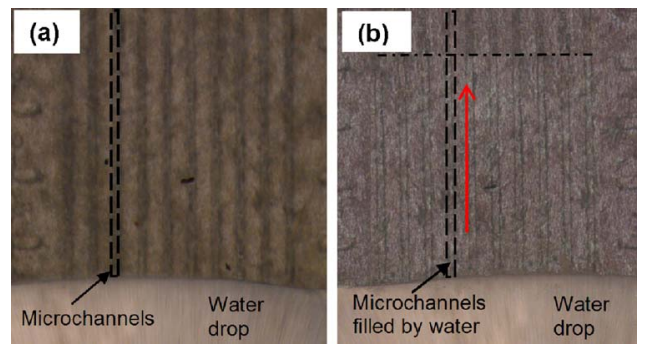

FIG. 4. (Color online) (a): Photograph of the edge of photoresponsive microchannels, with a water drop released and lying at the chip entrance without penetrating into hydrophobic capillaries. (b) Same area after local UV irradiation, with water filling microchannels along the direction indicated by the red arrow. The position of the water front is indicated by the horizontal dashed line. ing within microchannels [Fig. 4(b)] after switching on the UV laser converting the photochromic surface to its polar (MC) form.

In conclusion, we demonstrated the photocontrol of fluid penetration into polymer microchannels embedding photochromic molecules. TOPAS ${ }^{\circledR}$ was used as prototype polymer for microfluidic circuitry for its ease of processing combined with 6- $\mathrm{NO}_{2}$-BIPS. Such photoresponsive elements exhibited a decrease up to $20^{\circ}$ between the water contact angles of the native and the irradiated surfaces, which was exploited to induce reversible, photocontrollable changes of the wetting properties of microfluidic channels, and to enhance the fluid penetration rate up to $25 \%$. The realized photoactivable fluidic elements, presenting on-off valve behavior with optical control, can dramatically simplify the manipulation of liquids within microfluidic networks by removing the need for mechanical actuation parts.

The authors are grateful to the support of the Italian Institute of Technology and of the Italian Minister of University and Research through the FIRB projects RBLA03ER38 and RBIN045NMB.

${ }^{1}$ E. Delamarche, Adv. Mater. (Weinheim, Ger.) 17, 2911 (2005).

${ }^{2}$ A. M. Christenses, J. Micromech. Microeng. 15, 928 (2005).

${ }^{3}$ G. L. Liu, J. Kim, Y. Lu, and L. P. Lee, Nat. Mater. 5, 27 (2006).

${ }^{4}$ S. R. Sershen, G. A. Mensing, M. Ng, N. J. Halas, and D. J. Beebe, Adv. Mater. (Weinheim, Ger.) 17, 1366 (2005).

${ }^{5}$ P. Ben-Abdallah, A. O. E. Moctar, B. Ni, N. Aubry, and P. Sing, J. Appl. Phys. 99, 094303 (2006).

${ }^{6}$ N. Garnier, R. O. Grigoriev, and M. F. Shatz, Phys. Rev. Lett. 91, 054501 (2003).

${ }^{7}$ M. Ozhan, M. Wang, C. Ozhan, R. Flynn, A. Birkbeck, and S. Esener, Biomed. Microdevices 5, 61 (2003).

${ }^{8}$ J. Y. Shin and N. L. Abbott, Langmuir 15, 4404 (1999).

${ }^{9}$ G. Moller, M. Harke, H. Motschmann, and D. Presher, Langmuir 14, 4955 (1998).

${ }^{10}$ B. Coupe, M. E. Evangelista, R. M. Yeung, and W. Chen, Langmuir 17, 1956 (2001).

${ }^{11}$ A. M. Cazabat, F. Heslot, S. M. Troian, and P. Carles, Nature (London) 346, 824 (1990).

${ }^{12}$ R. H. Farahi, A. Passian, T. L. Ferrel, and T. Thundat, Appl. Phys. Lett. 85, 4237 (2004).

${ }^{13}$ M. K. Chaudhury and G. M. Whitesides, Science 256, 1539 (1992).

${ }^{14}$ B. S. Gallardo, V. K. Gupta, F. D. Eagerton, L. I. Jong, V. S. Craig, R. R. Shah, and Nicholas L. Abbott, Science 283, 57 (1999).

${ }^{15}$ T. L. Sun, G. J. Wang, L. Feng, B. Q. Liu, Y. M. Ma, L. Jiang, and D. B. Zhu, Angew. Chem., Int. Ed. 43, 357 (2004).

${ }^{16}$ G. M. Whitesides and P. E. Laibinis, Langmuir 6, 87 (1990).

${ }^{17}$ P. E. Laibinis, C. D. Bain, R. G. Nuzzo, and G. M. Whitesides, J. Phys. Chem. 99, 7663 (1995).

${ }^{18}$ M. K. Chaudhury and G. M. Whitesides, Science 256, 1539 (1992).

${ }^{19}$ B. Zhao, J. S. Moore, and D. J. Beebe, Science 291, 1023 (2001).

${ }^{20}$ E. Besson, A. Gue, J. Sudor, H. Korry-Youssoufi, N. Jaffrezic, and J. Tardy, Langmuir 22, 8346 (2006).

${ }^{21}$ J. Lahann, S. Mitragotri, T. N. Tran, H. Kaido, J. Sundaram, I. S. Choi, S. Hoffer, G. A. Somorjai, and R. Langer, Science 299, 371 (2003).

${ }^{22}$ K. Ichimura, S. K. Oh, and M. Nakagawa, Science 288, 1624 (2000).

${ }^{23}$ R. Rosario, D. Gust, M. Hayes, F. Jahnke, J. Springer, and A. A. Garcia, Langmuir 18, 8062 (2002).

${ }^{24}$ A. Athanassiou, M. I. Lygeraki, D. Pisignano, K. Lakiotaki, M. Varda, E. Mele, C. Fotakis, R. Cingolani, and S. H. Anastasiadis, Langmuir 22, 2329 (2006).

${ }^{25}$ J. C. Mcdonald and G. M. Whitesides, Acc. Chem. Res. 35, 491 (2002).

${ }^{26}$ A. Athanassiou, M. Kalyva, K. Lakiotaki, S. Georgiou, and C. Fotakis, Adv. Mater. (Weinheim, Ger.) 17, 988 (2005).

${ }^{27}$ E. Mele, M. Varda, D. Pisignano, M. Farsari, G. Filippidis, C. Fotakis, A. Athanassiou, and R. Cingolani, Appl. Phys. Lett. 88, 203124 (2006).

${ }^{28}$ Y. Xia and G. M. Whitesides, Angew. Chem., Int. Ed. 37, 1950 (1998).

${ }^{29}$ D. Mayers, Surface, Interfaces and Colloids (Wiley-VCH, New York, 1999), 97-123. at: hitp://scitation. aip.org/termsconditions. Downloaded to IP 